\title{
"Fronteiras e políticas que atravessam a identidade e a sociabilidade indígena": uma análise acerca dos sentidos das migrações Palikur na fronteira Brasil-Guiana Francesa
}

\author{
"Frontiers and policies that cross indigenous identity \\ and sociability": an analysis of the meanings of Palikur \\ migrations on the Brazil-French Guiana Border
}

\author{
Venâncio Guedes Pereira ${ }^{1}$ \\ Carmentilla das Chagas Martins ${ }^{1}$
}

DOI: http://dx.doi.org/10.20435/tellus.v19i39.579

\begin{abstract}
Resumo: O presente artigo tem como objetivo discutir a sociabilidade do povo Palikur, habitante da fronteira franco-brasileira a partir da concepção de identidade e de fronteira étnica, de forma a perceber como esses indígenas sofreram e lidaram com as políticas dos Estados brasileiro e francês após o Laudo Suíço de 1900. No tocante ao contato com as políticas dos Estados, os Palikur são obrigados a conviver com fronteiras impostas por não indígenas, que reverberam historicamente em sua sociabilidade, mas que, apesar do fator "identidade nacional", mantém a identidade étnica Palikur, utilizando as identidades francesa e brasileira justamente para se adaptarem à fronteira geopolítica, e usando os movimentos migratórios como artifício principal.
\end{abstract}

Palavras-chave: Palikur; fronteira Brasil-Guiana Francesa; identidade; migrações.

\begin{abstract}
This article has as objective to discuss the sociability of the Palikur people, inhabitant of the French-Brazilian Broder, from the conception of identity and ethnic border, in order to understand how the natives suffered and dealt with the policies of the Brazilian and French States after the Swiss Report of 1900. Concerning the contact with the policies of the States, the Palikur are obliged to live with boundaries imposed by non-Indians, that reverberate historically in their sociability, but which, despite the "national identity" factor, uphold the Palikur ethnic identity, using French and Brazilian identities precisely to adapt to the geopolitical frontier, and using migratory movements as the main artifice.
\end{abstract}

Keywords: Palikur; Brazil-French Guiana border; identity; migrations.

1 Universidade Federal do Amapá (UNIFAP), Macapá, Amapá, Brasil. 


\section{INTRODUÇÃO}

Os Palikur, etnia indígena do tronco linguístico Aruak, que habitam na fronteira entre Brasil e Guiana Francesa, mais precisamente nas cidades de Oiapoque (às margens do rio Urukauá, afluente da bacia do rio Uaçá), Saint-Georges, Régina, Roura e Macouria, apresentam uma sociabilidade bastante específica, observável no campo historiográfico das diversas populações autóctones que vivem em espaços transnacionais e convivem com imposições do Estado a partir de mecanismos sociais de cooptação, dentre eles a "identidade nacional" (CARDOSO DE OLIVEIRA, 2005). Nesse contexto, os Palikur, "donos" do espaço habitado (historicamente falando), lidam com tais mecanismos de controle político e social de ambos os Estados, sendo empurrados a buscar políticas públicas em ambos os territórios, acionando ora a identidade indígena brasileira, ora a identidade cidadã francesa.

Para observar as ações dos Estados nessa política de controle de indígenas na fronteira franco-brasileira, é importante destacar os movimentos migratórios dessas populações da região, seja para comércio, firmar moradia, fugir de guerras ou buscar auxílio do próprio Estado (MUSOLINO, 2006). Neste sentido, vale ressaltar que essa prática migratória faz parte das estratégias de sobrevivência dos Palikur, que, em diferentes recortes históricos, as utilizam para diversos fins, sempre ressaltando o movimento como tradicional e inerente à sua identidade como grupo étnico ${ }^{2}$. Para esta discussão, se poderia utilizar um recorte bastante longo (desde as investidas dos reis de Portugal e França nos séculos XVIII e XIX, por exemplo), mas nos limites deste artigo, se remeterá ao recorte temporal exatamente após o período do Contestado franco-brasileiro, ou seja, depois de 1900 - quando se teve um Estado com direito, de fato, sobre a terra contestada outrora - até o tempo presente.

Aspectos como a história dos Palikur e sua relação com os Estados brasileiro e francês, as estratégias de sociabilidade através dos fluxos migratórios e a qualidade do Palikur como um agente transeunte da fronteira (física e identitária) serão discutidos neste texto, em diálogo com estudos sobre os Palikur e trabalhos

\footnotetext{
2 Para Barth (2000, p. 27), "grupos étnicos são categorias atributivas e identificadoras empregadas pelos próprios atores". O autor ressalta que os grupos étnicos se formam a partir de várias características compartilhadas que se aglomeram, girando em torno da identidade como grupo a partir da socialização com outros grupos étnicos/sociais, definindo-os (BARTH, 2000, p. 27).
} 
de teorias antropológicas, com o objetivo de analisar as problemáticas causadas pelas políticas públicas dos Estados e apresentar uma interpretação a partir do conceito de identidade híbrida.

\section{HISTÓRICO DOS PALIKUR NO BRASIL (POLÍTICAS DO ESTADO E A PRESENÇA DA IGREJA)}

O final do século XIX e o início do século XX, com o estabelecimento do direito à terra contestada em favor do governo brasileiro mediante o Laudo Suíço de 1 o de dezembro de 1900, significou uma profunda mudança na vida dos Palikur e dos demais povos indígenas da região. A exemplo disso, documentos da época citam uma diminuição do deslocamento de povos Caribe e Aruak pela região, mostrando uma substancial mudança de vida, agora mais sedentária. Sobre o Laudo Suíço:

Em 1897, após anos de conflitos com várias baixas dos dois lados, um termo de compromisso, assinado por delegados do Brasil e da França, confiou a resolução do Contestado à arbitragem do presidente da federação Suíça, Walter Hauser. Os dois países, de um lado Brasil e do outro a França, reuniram a maior quantidade de arquivos possíveis para provar suas proposições [...] Após inúmeros estudos e conferências, a sentença foi pronunciada pelo governo suíço três anos mais tarde (1900), concedendo ao Brasil a posse definitiva da região litigiosa através do laudo suíço ou laudo de Berna. (SILVA; RUCKERT, 2009, p. 5).

Mesmo com a terra em mãos brasileiras, as tradicionais relações de comércio entre indígenas e franceses na fronteira transpassavam as questões do litígio entre as nações, e embora este caso já tivesse sido "resolvido" mediante a lei, os indígenas continuavam trocando mercadorias - fato que desagradava ao governo brasileiro -, principalmente os Palikur, que representavam um dos maiores contingentes populacionais indígenas da época, com 189 pessoas do lado brasileiro em 1926 (NIMUENDAJU, 1926, p. 48). O governo deu aval à proposta de Cândido Mariano Rondon, que era a de nacionalizar os indígenas da área e salvaguardar a fronteira, política esta que atravessou o século XX em muitas fronteiras nacionais com presença indígena no país. Nesse processo, tanto no Brasil quanto na Guiana Francesa, "ações protecionistas tomaram formas jurídicas e procuraram, através da cidadania, atrair as populações indígenas" (MUSOLINO, 2006, p. 13). 
Nesse período, era muito comum a escolha por políticas de nacionalização de populações em regiões fronteiriças, especialmente as indígenas, uma prática constante na recém-criada República brasileira. Na região do Alto rio Amazonas, na fronteira entre Brasil, Colômbia e Peru, a etnia indígena Ticuna também sofrera sanções e impactos por meio de políticas colonizadoras e nacionalizadoras dos Estados em fronteira, em processos muito similares aos vivenciados pelos Palikur. De acordo com López Garcés (2002), algumas instituições foram encarregadas deste trabalho:

La brasileñidad, peruanidad y colombianidad de los ticuna, entre otros pueblos indígenas asentados en esa región de fronteras, debieron ser construidas mediante los esfuerzos de diferentes instituciones que los diversos estados-nación de signaron para tal propósito. Destacamos el papel importante de los ejércitos nacionales en los procesos de brasilerización y peruanización de los indígenas, y el de la iglesia católica en el de colombianización de los mismos. (LÓPEZ GARCÉS, 2002, p. 79).

Sobre as relações sociais e comerciais dos Palikur com europeus, principalmente, com os franceses, remete-se ao que Barth (2000) escreve sobre fronteira étnica. Para ele, a manutenção da fronteira étnica se dá a partir de uma interação social (no caso dos Palikur, o uso da língua francesa para o comércio), em que, apesar do contato de culturas diferentes, tais grupos se mantêm como unidades. Em outros estágios, essas interações reduzem as diferenças, uma vez que "interação tanto requer como gera certa congruência de códigos e valores" (BARTH, 2000, p. 35). Em outras palavras, apesar de existirem diferenças culturais entre os Palikur e os europeus comerciantes, a concordância de códigos e valores (o próprio comércio e também a visão acerca dos portugueses e dos brasileiros como "inimigos") permitiu a interação entre eles, causando modificações e ressignificações entre os tratantes, ao modo particular de cada um. Para o Estado brasileiro, tais modificações eram nocivas à soberania da nação.

Com essas mudanças políticas na virada do século, o papel dos indígenas da fronteira foi repensado. Se antes a importância do contato com estes habitantes por parte de portugueses e franceses se dava por conta de mão de obra, influência na terra e comércio, agora o papel a ser incorporado pelos indígenas tomou uma proporção muito mais estratégica. Nos moldes positivistas da época, os indígenas se transformariam nos inspetores da fronteira, e as guardariam 
para o Estado brasileiro. Para isso, eles passariam por um profundo processo de nacionalização, onde a educação escolar, o ensino da língua nacional, a fixação e produção em terras brasileiras e o direito à saúde seriam todos oferecidos pelo governo, ou seja, o Estado tomaria para si a tutela dos indígenas em fronteiras.

Em 1930, após a indicação de Rondon sobre a necessidade da criação de um posto indígena e escola, foi criado o primeiro posto indígena do Serviço de Proteção aos Índios ${ }^{3}$ (SPI) na região do Uaçá, em um ponto geograficamente estratégico, chamado Encruzo (ponto de cruzamento entre os rios Curipi e Uaçá), local pensado por ser a porta de entrada das aldeias Galibi-Marworno e Palikur, e que serviu por anos como local de inspeção e revistas, principalmente à procura de bebidas alcoólicas transportadas por indígenas, aos quais o governo proibia o consumo.

O SPI é, sem dúvida, o primeiro grande representante do Estado brasileiro entre os Palikur. Nacionalizar, educar e agrupar os indígenas da região era parte da política de soberania do Estado. Observa-se, neste momento, que os indígenas usaram de estratégias para subterfugiar tal controle, como o contrabando e as diásporas para a Guiana Francesa (para fugir das leis brasileiras). Como a grande marca da "modernidade" republicana, que há pouco adentrara no país, era o discurso de progresso em detrimento ao Palikur "primitivo", toma-se a discussão de Martins (2014) sobre as temporalidades históricas, que, por serem tão díspares, ao se encontrarem ocasionam diferença, conflito.

Com o objetivo de "progredir" com os indígenas, o SPI, representado pela figura de Eurico Fernandes, também fazia um trabalho de fiscalização no posto do Encruzo, não só para impedir o "contrabando" de mercadorias produzidas pelos indígenas no Brasil, mas também para diminuir cada vez mais o contato com os franceses. Fernandes (1953) relata que, em 1931, primeiro ano em que esteve entre os Palikur no posto do SPI, a população era de 202 pessoas, dentre elas: 59 homens, 65 mulheres, 32 menores do sexo masculino e 46 menores do sexo feminino. O mesmo autor argumenta que em 1943, doze anos após o início do

\footnotetext{
3 A presença do SPI no Uaçá mudou o panorama social dos indígenas da região, pois interferiu na produção econômica, principalmente na introdução de outras espécies de cultivos; fortaleceu a representação dos caciques; e junto ao regime nas escolas, estabeleceu a prática de castigos morais e físicos a quem era contra as normas instituídas pelo órgão (CAPIBERIBE, 2007).
} 
trabalho do órgão na região, os números eram diferentes, 273 pessoas divididas em 67 homens, 66 mulheres, 88 menores do sexo masculino e 52 menores do sexo feminino. É interessante perceber o discurso político nacionalista na fronteira, muito presente nos relatórios do SPI, inclusive naquele escrito por Fernandes, uma vez que justifica o crescimento populacional dos Palikur graças ao trabalho realizado pelo órgão no Uaçá:

É natural que perseguidos, espoliados, caçados, etc. [...] fatalmente desaparecerão; porém protegidos, tratados, evitando-Ihes os vícios, notadamente $o$ álcool, dando-Ihes as terras e os meios de que necessitam, curando-se-Ihes as enfermidades e o organismo combalido pela verminose, o resultado será o aumento de sua população, resultado de primordial interesse e benefício para a Pátria e a Humanidade. (FERNANDES, 1953, p. 284).

Nos anos de 1950 até o final dos anos de 1960, a ação do SPI no Oiapoque perdeu força, principalmente em decorrência da diminuição de sua verba de manutenção e de administrações corruptas; e aos poucos perdeu também credibilidade. Em 1967, o SPI foi extinto, e em seu lugar foi criada a Fundação Nacional do Índio (FUNAI).

Além da forte presença do Estado, outro fator de contato que modificou a sociabilidade Palikur foi o cristianismo. Historicamente é difícil apontar um marco histórico específico para determinar o início das tentativas de evangelização dos Palikur, seja por franceses, portugueses e brasileiros ou de qualquer outra nação. Curt Nimuendaju, em sua pesquisa na região do Oiapoque em 1926, fez uma importante análise dos Palikur no início do século XX citando "trapos da religião cristã" como o batismo da população pelo então vigário de Saint-George, o uso das palavras "Ohogri e Wapetpiy" e o enterro cristão, para explicar a presença do cristianismo "dos jesuítas" de décadas passadas pela região (NIMUENDAJU, 1926, p. 45). O autor indica que, apesar destas práticas, a cristandade Palikur acabava por aí, pois não havia capelas, nem imagens de santos e muito menos conhecimento da doutrina cristã entre a população (NIMUENDAJU, 1926, p. 45) . Em uma passagem específica, o autor nos aponta sob quais doutrinas religiosas os Palikur viviam a época de sua pesquisa, o que nos ajuda a concluir que as

4 Ohogri, traduzido para o Creole como "bom dié" (meu Deus); Wapetpiy, traduzido para o Creole como "diab" (Diabo) (NIMUENDAJU, 1926, p. 45). 
mudanças mais significativas entre os Palikur, das quais se apresentam até hoje, tenham ocorrido a partir da segunda metade do século XX:

Ao lado destes trapos da religião cristã ainda se conserva, como unidade perfeita, a antiga crença: a religião dos pajés. Esta não trata de Ohogri e Wapetpiy, mas se ocupa exclusivamente com os demônios da montanha e da água que povoam em bandos o país, e com os espíritos dos mortos, especialmente os dos finados pajés [...] Toda ação dos pajés se resume num manobrar constante dos demônios e espíritos defuntos, amigos uns, inimigos outros; todo engenho destes pajés consiste em saber trata-los com jeito e saber jogá-los manhosamente uns contra os outros. (NIMUENDAJU,1926, p. 46).

O cristianismo se instalaria de fato no Urukauá em meados da década de 1960, com o casal de norte-americanos Harold e Diana Green, a serviço do Summer Institute of Linguistics (SIL). Os missionários foram à comunidade com o objetivo de conhecer os indígenas, estudá-los, traduzir o evangelho bíblico para a língua nativa dos Palikur, o Parikwaki, e evangelizá-los. De acordo com os próprios Palikur, na década de 1950 ocorreram as primeiras tentativas, com missionários e outras Igrejas evangélicas, de uma aproximação com os indígenas, mas foi com o casal Green que "começava então uma obra que teria longa duração e cujos resultados seriam profundos" (CAPIBERIBE, 2007, p. 167).

O trabalho da SIL no Urukauá teve início nos anos 1950, com as primeiras tentativas do órgão de trabalhar com os indígenas da região, porém a autorização só foi concedida a eles pelo governo brasileiro mais de uma década depois, "através de um convênio com a divisão de educação, primeiro do SPI e posteriormente da FUNAI, sob a rubrica "sub-programa Palikur" e também sob o convênio firmado entre SIL e o Museu Nacional" (CAPIBERIBE, 2007, p. 168). O convênio autorizava os agentes a realizarem seu trabalho missionário, enquanto deveriam colher dados linguísticos dos indígenas e construir um material para o Museu Nacional, dentre eles um dicionário Palikur/Português. O início do trabalho do casal Green foi se ambientar ao modo de vida dos Palikur, fazendo sua ação evangelizadora da forma mais sutil possível, e da mesma estratégia ganhar confiança da comunidade.

Mesmo com o trabalho dos Green entre os Palikur, foi outro evento que definitivamente transformou a percepção dos Palikur quanto à religião cristã. Em 1980, um pastor chamado Glen Johnson, membro da News Tribes Mission (NTM), 
em uma viagem à Argentina, acabou tendo problemas em sua embarcação, e após ser avisado por um guarda de Clevelândia de que havia indígenas "ainda não alcançados" na região, resolveu desembarcar no Urukauá e realizar uma incursão. Neste momento, os Green estavam afastados do Urukauá, e então o pastor Jonhson, que não conhecia o português e tampouco o Parikwaki, precisou de um tradutor Palikur, e contou com a ajuda de Paulo Orlando, um dos líderes da comunidade Palikur e que, inclusive, foi um importante interlocutor indígena para o casal Green e se tornou um dos representantes da religião protestante no Uaçá.

No final da década de 1970, na gestão de Paulo Orlando como cacique e chefe do posto da Funai, a primeira Igreja evangélica da Assembleia de Deus (IEAD) foi levada para o Urukauá, com a ajuda do pastor da IEAD do Oiapoque e da IEAD de Macapá. Os Palikur assimilaram a nova vida como cristãos ao longo do tempo, como um processo que, a princípio, subsistia com a religião pagã, própria dos indígenas. Neste contexto, o elo principal entre o mundo dos homens e o mundo dos deuses entre os indígenas do Oiapoque era a figura do xamã (Pajé):

O xamanismo é no baixo Oiapoque um conjunto de teorias e práticas que possibilitam a administração de relações entre domínios cosmológicos diversos onde estão pessoas igualmente diversas. Trata-se de interferir na entropia cósmica a favor da sociedade e dos homens, manipulando, negociando, controlando ou agenciando as múltiplas psyches (intencionalidades) com as quais o pajé lida. (ANDRADE, 2007, p. 109).

O xamã é o provedor dos poderes da cura, do feitiço, salvação e respostas diversas para quaisquer dúvidas dos indígenas. A presença da Igreja no Urukauá transformou a forma com que os Palikur viam o xamã, e esse momento representou um divisor de águas na vida dos Palikur. A partir dos anos de 1960, quando o trabalho missionário ainda não estava consolidado, até meados dos anos de 1980, muitos vestígios da mudança acabaram aparecendo:

Uma desconfiança recíproca ocorre entre os Palikúr, no que diz respeito a prática de malefícios, envolvendo não raro até parentes próximos. Em vista disso, procuram evitar o mais possível comer em casas de terceiros receando estar a comida enfeitiçada, salvo nos mutirões onde as refeições ocorrem coletivamente. Invariavelmente, costumam lançar as sobras das refeições nos cursos d'agua, a fim de não serem colhidas para algum desafeto para utilizá-las nas práticas do mal. [...] os Palikúr conhecem numerosos remédios nativos e formas de tratamento próprio, mas consideram as enfermidades 
"Fronteiras e políticas que atravessam a identidade e a sociabilidade indígena": uma análise acerca dos sentidos das migrações Palikur na fronteira Brasil-Guiana Francesa

como essencialmente causadas por forças demoníacas. (ARNAUD, 1984, p. 39).

Este relato recolhido por Expedito Arnaud em 1984 demonstra alguns aspectos muito interessantes para se pensar o processo de mudança e ressignificação que os Palikur viviam perante suas práticas religiosas. Observa-se, no relato, um medo de comer na casa de outras pessoas, pelo fato de poder a comida estar enfeitiçada. Em primeiro lugar, o xamã sempre despertou entre os indígenas da região do Uaçá o sentimento de respeito, por ser detentor de tantos dons considerados "divinos", e também o sentimento do medo, uma vez que este poderia ser o responsável pela cura ou pelo feitiço que uma determinada pessoa sofrera, o que poderia se desenvolver em uma sucessão de acusações, feitiço contra feitiço, e também em uma guerra movida a vinganças. Sendo assim, o choque com a religião evangélica teve seu alvo justamente nas ações do xamã, uma vez que, para a Igreja, só Deus pode curar, e este, por sua bondade e misericórdia, não amaldiçoa.

Em 1984, quando o fato foi relatado por Arnaud, a época era de transição entre os Palikur, o que torna o "medo" dos feitiços e a citação de uma "causa demoníaca" nestas práticas uma clara alusão de interpretação do xamã como um agente "não cristão", e esta interpretação, sem dúvida, demonstra que a religião evangélica ganhava adeptos no decorrer das décadas posteriores à chegada do casal Herold e Diana Green no Uaçá. A partir da conversão em massa dos Palikur (principalmente entre os anos de 1970 e 1980), naturalmente o xamã se tornou uma figura cada vez mais afastada desta nova realidade comunitária. Este processo se deu, pois, o pentecostalismo/cristianismo propôs aos Palikur uma configuração social diferente da vivida antes, e isto explica o afastamento do xamã do "centro" cultural do seu povo, ou seja, o agente que detinha os principais conhecimentos e era a referência das ações deste povo passou a ser visto como principal causador de uma vida marcada por agressões, revides, vinganças e discussões.

Ao modo particular de vida dos Palikur podemos observar que a religião evangélica se torna central como detentora dos costumes, sendo também importante em suas representações, pois o crente fiel é quem melhor representa o ideal Palikur do tempo presente. Apesar desta realidade, a religião tradicional Palikur não pode ser dita como totalmente excluída, tampouco esquecida, mas 
encontra-se num estado que pode ser descrito como de apaziguamento, no qual os crentes percebem um perigo de retorno iminente de um mundo que por meio da religião haviam se esforçado por esquecer (CAPIBERIBE, 2007).

As transformações indicadas nas ações do Estado brasileiro e na evangelização cristã levada a efeito por igrejas evangélicas modificaram desde a paisagem das aldeias até os aspectos culturais mais profundos, dos quais talvez ainda nem tenhamos percebido. O século XXI se apresenta com a mesma realidade vivida pelas comunidades indígenas nos quatro séculos que antecedem o atual: uma aproximação de indígenas e não indígenas cada vez mais forte, seja nas cidades ou nas terras indígenas, e também as exposições contemporâneas das mais variadas culturas indígenas do Brasil. Por certo, os Palikur não seriam excluídos dessa realidade, e viveriam nos primeiros anos da década de dois mil, eventos que os levariam para além das fronteiras por eles já vividas em sua história.

\section{A CIDADE DE OIAPOQUE E AS DINÂMICAS NA FRONTEIRA}

Os Palikur são do tronco linguístico Aruak e indicados por Vidal (2001) como habitantes originários de toda região, atualmente denominada de franco-brasileira. Em sua organização social encontram-se clãs patrilineares exogâmicos. Eles vivem em aldeias tanto no Brasil, quanto na Guiana Francesa, sendo regular o contato entre as aldeias; portanto, os Palikur têm vivências caracterizadas pelo que denominamos de práticas de atravessamento da fronteira política. Como demonstrado anteriormente, estão conververtidos a religião Petencostal há mais de três décadas e mantêm poucos rituais indígenas, no entanto possuem um “acervo importante de mitos e 'histórias dos antigos', além de uma rica cultura material (VIDAL, 2001, p. 119).

Como se depreende o uso do termo "sentidos das migrações" faz-se necessário como chave de interpretação devido à complexidade das relações sociais na fronteira Brasil-Guiana Francesa, sentida, em especial, pelas comunidades indígenas que residem na região. Essa complexidade se encontra em vários aspectos, sobretudo na dicotomia existente nos acordos de cooperação e nas constituições sociais e históricas de França e Brasil.

O município brasileiro de Oiapoque, que fica no extremo norte do Amapá, é constantemente relatado por pesquisadores (PINTO, 2008; MARTINS, 2009; 
OLIVEIRA; 2011) como um local de grande fluxo de pessoas, dos mais variados estados brasileiros, que chegam à cidade em busca de emprego. Outra recorrente característica é o fato de que a cidade se encontra em um lento desenvolvimento urbano e humano, com precariedade de bens públicos e forte presença da iniciativa privada, com lojas de roupas, hotéis, restaurantes etc. De acordo com Pinto (2008, p. 82), "a presença do Estado brasileiro nesta região está longe de ser qualificada, e ainda é extremamente frágil. Apesar das instituições estarem presentes na região, tem-se a impressão que elas existem apenas por uma exigência constitucional".

Esta observação permite pensar a realidade migratória na região. Em busca de oportunidades diversas, desde o trabalho formalizado (por meio de documentação e visto francês) até os trabalhos informais (como a prostituição e o garimpo), brasileiros atravessam a fronteira, sendo frequentemente remanejados ao Brasil pelo governo francês. Este movimento ocorre desde, pelo menos, a década de 1960, desde a construção do centro aeroespacial da cidade de Kourou (FR), quando o governo francês incentivou a ida de brasileiros para o país, com a finalidade de obter mão de obra barata para suas obras públicas (PINTO, 2008; OLIVEIRA, 2011).

Desde o Laudo Suíço de 1900, as relações entre Brasil e Guiana Francesa são vivenciadas a partir da indiferença (CERVO, 2002 apud MARTINS, 2016), o que só veio mudar a partir do Acordo Quadro de Cooperação, assinado pelos presidentes do Brasil e da França, respectivamente, Fernando Henrique Cardoso e Jacques Chirac, em 1996. Sobre tal acordo:

A institucionalização da cooperação transfronteiriça franco-brasileira carrega em seu bojo propostas que pretendem estimular ações conjuntas para o desenvolvimento socioeconômico sustentável nas coletividades situadas de um lado e outro do rio Oiapoque, limite natural e divisor das soberanias. (MARTINS, 2016, p. 38).

Apesar do acordo firmado, Martins (2016) aponta que é na problemática existente nas migrações brasileiras para a Guiana que se encontram os maiores constrangimentos no acordo. Na verdade, a cooperação foi pensada no campo da diplomacia das Relações Internacionais, deixando de lado as questões mais emergentes no trato da fronteira, a dizer, o movimento migratório de franceses ao Brasil, em busca de produtos e bens mais baratos, e, sobretudo as migrações brasileiras para a Guiana Francesa, que historicamente são criminalizadas pelo Estado francês. Na verdade, o exercício do acordo não contemplou a cotidia- 
nidade, tampouco a realidade social na fronteira e o fluxo intenso de ambos os lados.

Neste contexto de discrepância socioeconômica entre Oiapoque e Guiana Francesa, os Palikur se dividem em comunidades em ambos os países, constituindo uma população de significativo contingente populacional. Esse dado permite aos Palikur um trânsito constante, uma vez que os fluxos migratórios indígenas não sofrem as mesmas sanções burocráticas dos não indígenas.

No município de Oiapoque, o território habitado pelas populações indígenas é constituído por espaços demarcados e homologados pelo governo federal na forma de Terras Indígenas. Os Palikur vivem juntos aos Karipuna e aos Galibi Marworno nas Terras Indígenas Uaçá I e II, homologadas em 1991 pelo Decreto Lei n. 298 de 29/10/91, publicado no DOU em 30/10/91, com 470.164ha ${ }^{5}$ (CAPIBERIBE, 2007, p. 121). Os Palikur dividem a terra indígena em treze aldeias, e dentre elas a mais populosa é a aldeia Kumenê, com novecentos e vinte habitantes. Tais aldeias são tradicionalmente construídas em torno de um centro administrativo, representado pelo Paytuempu Akivara (fundador da aldeia) que geralmente é o homem mais velho a ali residir e é pai do próximo Paytuempu ou sogro deste e necessariamente tem de viver próximo do genro, como uma relação de respeito, aprendizado e trabalho (CAPIBERIBE, 2007).

Ao contrário do Brasil, na Guiana Francesa não há terras indígenas, e dessa forma os Palikur vivem em pequenas comunidades ao redor das cidades de Régina, Roura e Macouria. O maior contingente populacional Palikur vive na cidade de Saint-Georges de l'Oyapock e o local por eles ocupado nesta cidade é um espaço comum, chamado Village Esperánce ${ }^{6}$, onde se organizam em forma de pequenos bairros, divididos em Village I e Village II. O Village I é o mais antigo, e a Igreja predominante é a Adventista do Sétimo Dia (IASD), enquanto no Village II predomina a Assembleia de Deus. Além disso, cada Village tem seu Paytuempu Akivara, nos

5 A terra indígena Uaçá I e II, somada às terras indígenas Galibi (homologada em 1982) e Juminã (homologada em 1992), formam as Terras Indígenas do Oiapoque (CAPIBERIBE, 2005).

6 Capiberibe relatou em 2009 o surgimento do que ela chamou de Village Experánce III, em um lugar desprovido de saneamento básico, com estrutura muito simples, contendo "quatro moradias e duas casas de farinha" (CAPIBERIBE, 2009, p. 253). Faz-se esta citação, pois no próprio escrito as informações se encontram em um estágio bastante superficial, mas que pelo fato de ter sido relatado há oito anos atrás, há boas possibilidades de este Village ter ganho dimensões espaciais e populacionais maiores. 
"Fronteiras e políticas que atravessam a identidade e a sociabilidade indígena": uma análise acerca dos sentidos das migrações Palikur na fronteira Brasil-Guiana Francesa

moldes da organização social dos Palikur do lado brasileiro:

Esses espaços estão localizados de maneira contígua na periferia da pequena cidade de Saint-Georges de l'Oyapock. A configuração e a composição do bairro Palikur, com as casas dos genros localizadas próximas às casas dos sogros, em muito lembram as aldeias no Urukauá. (CAPIBERIBE, 2009, p. 6).

O Village II foi formado em meados dos anos de 1980, por indígenas Palikur que saíram do Urukauá em um dos vários momentos de crise da religião cristã entre eles. Esta crise, que teria ocorrido entre os anos das décadas de 1970 e 1980, marcou o "desvio" de muitos fiéis da Igreja evangélica, motivando alguns indígenas a saírem do local, com o objetivo de se "manterem na fé". Nas duas vilas, a Igreja é a construção central, além de uma praça, que serve de centro das ações coletivas, e a periferia da vila, onde se localiza a esfera social doméstica.

Como se pode perceber, há diferenças entre ser um indígena no Brasil ou na Guiana Francesa, porém as mais significativas são percebidas quando se observam os direitos que o indígena goza aqui ou lá. No Brasil, na "legislação ordinária destaca-se o chamado Estatuto do índio (Lei n. 6001 de 19/12/1973), que regula os detalhes dos direitos indígenas" (CUNHA, 2012, p. 128). Dentre tais direitos, destaca-se o direito às Terras Indígenas (Decreto n. 1.775, de 8 de janeiro de 1996), as quais, no caso dos povos indígenas do Amapá, são todas homologadas. No que diz respeito à identidade, os Palikur não precisam abdicar de sua indianidade ${ }^{7}$, tampouco de sua nacionalidade, e ambas são acionadas tão logo necessitam de direitos políticos e amparos legais diversos, cuja responsabilidade advém do Estado (além das Terras indígenas, escolas, saneamento básico, saúde pública etc.).

A dinâmica na Guiana Francesa é completamente diferente, pois não há direitos diferenciados a partir da identidade étnica dos povos, tanto na metrópole quanto nesta coletividade territorial do ultramar francês. Sobre o indígena na Guiana Francesa:

7 Utiliza-se aqui o conceito de "indianidade" definido por Baines (2004), na relação dos indígenas da fronteira Brasil-Guiana, onde "surgem diversas formas de se identificar como índio, mestiço, Makuxi, Wapichana, brasileiro, ou guianense, que muitas vezes se sobrepõem, aparecendo, à primeira vista, contraditórias da perspectiva de um estranho, mas não da perspectiva dos povos indígenas que vivem nesta fronteira, pois não vêem nenhum problema em se identificar conforme os contextos em que estão imersas e lhes parecem naturais" (BAINES, 2004, p. 11-12). Ressalta-se no referido termo, o caráter de ação dos próprios indígenas, que determina sua própria visão de quem é, não dependendo do "outro". 
[...] seguindo os preceitos constitucionais, cada Palikur imigrante é alvo de uma política de assunção de cidadania que o envolve e seduz através de benefícios sociais oferecidos pelo Estado francês, mas que o alija de sua matriz identitária ou forma-síntese identitária, tornando-o compatível de sua forma de sujeito de direito civil. Isto é: torna-se apenas cidadão francês que deixa legalmente de ser índio, porém não deixa de ser membro de uma comunidade étnica. (MUSOLINO, 2006, p. 15).

Uma vez instituída a fronteira geopolítica, as mudanças na sociabilidade dos Palikur passaram a ser percebidas na forma como eles buscam os subsídios básicos para sua sobrevivência em ambos os lados, sempre na relação de contato com outros povos (indígenas e não indígenas), com o Estado e instituições, como o SPl ${ }^{8}$ e a $\mathrm{FUNAl}^{9}$, ou em programas de integração e religiosos ${ }^{10}$. A partir da análise de Shalins (1997) a respeito de sistemas translocais, os Palikur migram de um lado para outro, em um movimento que subsidia as famílias que ficam no lugar de origem, e que necessitam desse trânsito para conseguirem dinheiro e manterem fortificados os laços fraternais com os parentes étnicos. Sobre os sistemas translocais:

Culturalmente focalizada na terra natal, e estrategicamente dependente dos lares periféricos no estrangeiro, a estrutura é assimétrica de duas maneiras opostas. Considerada como uma totalidade, a sociedade translocal está centrada em suas comunidades indígenas e orientada para elas. Os imigrantes identificam-se com seus parentes na região de origem, e é a partir dessa identificação que se associam transitivamente entre si no estrangeiro. Esses habitantes da cidade e do mundo exterior permanecem ligados a seus parentes na terra natal, especialmente por entenderem que seu próprio futuro depende dos direitos que mantêm em seu lugar de origem. Assim,

8 O SPILTN, Serviço de Proteção ao Índio e Localização dos Trabalhadores Nacionais, transformado em Serviço de Proteção ao Índio em 1918, foi criado pelo governo do Brasil para promover a integração racional das populações e territórios indígenas à sociedade brasileira; ou seja, transformar o índio em membro do corpo político nacional (BIGIO, 2007).

9 A Fundação Nacional do Índio foi criada em 1967, tendo como premissa o inevitável fim do índio no Brasil. Disso decorria a concepção da transitoriedade da condição de indígena, bem como de seu desamparo, o que os associava à tutela da FUNAI (BIGIO, 2007).

${ }^{10}$ Faz-se uma observação a respeito da relação "Estado e agentes religiosos". Interpreta-se dessa forma, pois, como foi explicado, o casal Green adentrou nas aldeias Palikur a partir de acordos entre eles e o governo, mediados pelo Museu Nacional. Pensa-se que, nesse sentido, mesmo que os resultados da religião não sejam de competência direta do Estado, este foi preponderante na "gênese" do protestantismo entre os Palikur. 
o fluxo de bens materiais favorece em geral os que ficaram em casa: estes se beneficiam dos ganhos obtidos e das mercadorias adquiridas por seus parentes na economia comercial externa. (SAHLINS, 1997, p. 115-6).

Observa-se os Palikur no sistema translocal, pois suas práticas são, antes de tudo, ligadas à tradição do deslocamento livre entre as duas margens do rio Oiapoque. Na conjuntura atual, em que Ihes falta subsídios no Brasil, mas também na Guiana Francesa (principalmente na procura por terra), há membros do grupo que migram em busca de dinheiro e opções para sustento da sua família, que fica à espera do retorno. No local de destino, seus parentes étnicos os recebem, os auxiliam e os ajudam a formar suas estratégias de obtenção de bens e recursos. Essa aliança cooperativa é observada em ambos os lados, uma vez que, tanto no Brasil quanto na Guiana Francesa, as populações indígenas constituem "grupos diferenciados no âmbito das sociedades globais, vindo a ocupar, em regra, posições subalternas" (CARDOSO DE OLIVEIRA, 2005, p. 9).

No que diz respeito às funções exercidas pelos Palikur brasileiros na Guiana Francesa, é importante ressaltar que os Palikur franceses são alvo de uma política de financiamento agrícola pelo governo, o que lhes garante um espaço no mercado formal, dando-lhes condições de oferecer suporte para os parentes étnicos do Brasil. Além disso, boa parte da população indígena do país é beneficiada por empregos temporários, como os de limpeza pública, de obras públicas e de serviços agrícolas. Os brasileiros atravessam a fronteira e passam a substituir os franceses nos trabalhos informais, como na roça, venda de animais, plantação e venda de mandioca e farinha. Enquanto os franceses trabalham temporariamente para o governo, os brasileiros não deixam o trabalho informal cair. Os lucros das vendas informais são divididos.

Esses acordos viabilizam a estadia dos Palikur do Brasil na Guiana Francesa, mas não garantem a sua permanência por muito tempo. Para terem direito às políticas públicas francesas, os indígenas têm de abdicar de sua identidade étnica e têm de se submeter às normas do Estado francês. Não há opção para eles, pois "as políticas de assunção de uma ou outra cidadania em ambos os países são taxativas: ou se é francês ou se é brasileiro, não existindo margem para dupla cidadania" (MUSOLINO, 2006, p. 64). Esta realidade os obriga a estarem em constante movimento, ficando o tempo permitido para ganhar um pouco de dinheiro, levá-lo para casa e depois fazerem o mesmo trajeto em outra temporada. 
Pensar os "sentidos das migrações" serve como parâmetro para se observar as motivações de indígenas, brasileiros, sul-americanos e franceses metropolitanos em migrar, em buscar do outro lado o que não têm do seu lado. Martins (2016) explica que os países que se propõem a cooperar encontram-se contíguos territorialmente, mas também se encontram afastados no tocante à história e ao desenvolvimento. Isso implica uma realidade de igualdade nunca ajustável entre os países, o que os leva a reforçarem as forças militares e de impedimento de fluxo nas fronteiras, aumentando cada vez mais as disparidades entre eles. É justamente o paradoxo entre as possibilidades de fluxo e as barreiras postas na fronteira que dão sentido à mobilidade (ODGERS; DELGADO, 2011).

\section{CONSIDERAÇÕES FINAIS}

Ao se analisar a sociabilidade peculiar que a fronteira Brasil-Guiana Francesa impõe às populações indígenas da região, observam-se diversos pontos os quais permitem pensar múltiplas fronteiras impostas e transpassadas por estes agentes. Os Estados historicamente planejaram transformar as populações indígenas em agentes fronteiriços, dando-lhes educação (principalmente o ensino da língua nacional), saúde pública e víveres básicos, o que, de certa forma, pode-se interpretar como políticas de controle social, uma forma de impedir que essas populações procurem tais políticas do outro lado da fronteira.

As políticas se modificaram ao longo dos anos, porém, os efeitos das políticas atuais forçam os Palikur a buscarem melhores condições de vida em lugares onde, em muitas situações, são vistos como estrangeiros, mão de obra desqualificada e população que não rende lucros ao Estado. Se antes era importante cooptá-los para a proteção e soberania da terra, o que implicava impedi-los de migrar, hoje as políticas permitem a sua migração, mas não são menos nocivas. Os Palikur, por não serem donos, por direito, de terras na Guiana Francesa (a não ser que as comprem) vêm às Assembleias indígenas do Oiapoque com o intuito de debater e absorver, das discussões com as lideranças indígenas brasileiras, orientações políticas que os situem por meio da identidade étnica. A fronteira geopolítica foi posta por outros. Coube aos Palikur vivê-la, negociando identidade e se adaptando a tais medidas.

Mas afinal, na fronteira identitária entre ser brasileiro e ser francês, aonde se encontra a identidade Palikur? Estaria ela fadada ao desaparecimento por 
conta do contato incisivo e inerente com o aparelho "nacionalizador" do Estado? Na verdade, há que se considerar outros aspectos nesta relação que transpassa a fronteira geopolítica. De acordo com Barth, as dicotomias étnicas não se estabilizam no isolamento social, pelo contrário, elas se dão no contato com o outro, pois "as distinções étnicas não dependem da ausência de interação e aceitação sociais mas, ao contrário, são frequentemente a própria base sobre a qual sistemas sociais abrangentes são construídos" (BARTH, 2000, p. 26). O autor chama esse encontro de diferentes povos e modos de vida de fronteira étnica.

A fronteira entre o Amapá e a Guiana Francesa, como outras do território brasileiro, tem significados diversos, constituídos em práticas sociais e/ou culturais históricas. Nessa fronteira prevalecem contextos de subsistência assinalados por precariedades e carências, os quais "empurram" o Palikur para o outro lado da fronteira sempre em busca do que lhe falta no seu local de moradia. A migração Palikur torna-se, portanto, estratégica no que se refere à assistência governamental, não importando se do lado do Brasil ou do lado da Guiana Francesa. Essas escolhas, em favor de serem assistidos pelo governo, exprimem vivências para habitar em trânsito, nas quais o fluxo migratório qualifica a fronteira como centro de hibridização. De acordo com Odgers e Delgado (2011), a fronteira como local de diferenças culturais, contrastes e diversos emblemas identitários, transforma o transeunte em um sujeito híbrido, ou seja, um sujeito em trânsito, que necessita do outro lado para a realização de suas atividades, mesmo que este lugar seja o estrangeiro.

Tais fronteiras atravessam os Palikur, mas fazem parte de fronteiras perceptíveis, e não são as únicas. A partir da fronteira étnica pode-se entender que a identidade Palikur, mesmo colocada em tantas situações históricas, mantém-se viva, ressignificando símbolos nacionais impostos por brasileiros e franceses, o que permite a sua persistência justamente por estar em contato com aspectos culturais diferentes. Por mais que historicamente os Estados tenham tentado nacionalizar as etnias indígenas da região, a identidade étnica lhes permite estarem em trânsito na fronteira, nunca a abandonando totalmente, e acionando seus mecanismos legais de cidadania quando necessitam, mediante o contato com o outro, tornando-se o indígena um sujeito híbrido, com identidade de fronteira. 


\section{REFERÊNCIAS}

ANDRADE, Ugo Maia. O real que não é visto - xamanismo e relação no Baixo Oiapoque (AP). 2007. 338 f. Tese (Doutorado em Antropologia Social) - Universidade de São Paulo, São Paulo, 2007.

ARNAUD, Expedito. Os índios Palikur do rio Urucauá: tradição tribal e protestantismo. Belém, PA: Museu Paraense Emílio Goeldi, 1984. 82p. (Publicações avulsas do Museu Paraense Emílio Goeldi, n. 38).

BAINES, Stephen Grant. Indianidade e nacionalidade na fronteira Brasil-Guiana. Brasília, DF: Departamento de Antropologia, Universidade de Brasília, 2004. (Série Antropologia, n. 360)

BARTH, Fredrik. O guru, o iniciador e outras variações antropológicas. Organização de Tomke Lask. Rio de Janeiro: Contra Capa Livraria, 2000. 243p.

BIGIO, Elias dos Santos. A ação indigenista brasileira sob influência militar e da Nova República (1967-1990). Revista de Estudos e Pesquisas FUNAl, Brasília, v. 4, n. 2, p. 1393, dez. 2007. Disponível em: http://www.funai.gov.br/arquivos/conteudo/cogedi/pdf/ revista_estudos_pesquisas_v4_n2/Artigo_1_Elias_Bigio_A_acao_indigenista_brasileira_ sob_a_influencia_militar_e_da_NovaRepublica_(1967-1990)1.pdf. Acesso em: 10 ago. 2018.

CAPIBERIBE, Artionka. Nas duas margens do rio: alteridade e transformações entre os Palikur na fronteira Brasil/Guiana Francesa. Rio de Janeiro: PPGAS-MN/UFRJ, 2009. 425p.

CAPIBERIBE, Artionka. Batismo de fogo: os Palikur e o Cristianismo. São Paulo: Annablume/ Fapesp/Nuti, 2007. 276p.

CARDOSO DE OLIVEIRA, Roberto. Introdução. In: CARDOSO DE OLIVEIRA, Roberto; BAINES, Stephen Grant (Org.). Nacionalidade e etnicidade em fronteiras. Brasília: Editora Universidade de Brasília, 2005. p. 9-20. (Coleção Américas)

CUNHA, Manuela Carneiro da. Índios no Brasil: história, direitos e cidadania. 1. ed. São Paulo: Claro Enigma, 2012. 158p.

FERNANDES, Eurico. PARIUCUR-IENE - Notas tiradas do livro Pariucur-lene (Ensaio) EURICO FERNANDES 1931-1945. In: RONDON, Cândido Mariano da S. Índios do Brasil: das cabeceiras do rio Xingu, dos rios Araguaia e Oiapoque. Rio de Janeiro: Ministério da Agricultura- CNPI, 1953. v. II, p. 283-92. 
"Fronteiras e políticas que atravessam a identidade e a sociabilidade indígena": uma análise acerca dos sentidos das migrações Palikur na fronteira Brasil-Guiana Francesa

LÓPEZ GARCÉS, Claudia Leonor. Los Ticunas frente a los procesos de nacionalización en la frontera entre Brasil, Colombia y Perú. Revista Colombiana de Antropología, Bogotá, v. 38, p. 77-104, jan./dez. 2002.

MARTINS, Carmentilla das Chagas. A migração internacional nos quadros da cooperação transfronteiriça franco-brasileira. Fronteiras \& Debates, Macapá, AP, v. 3, n. 1, p. 37-66, jan./jun. 2016. Disponível em: https://periodicos.unifap.br/index.php/fronteiras/article/ view/3409/carmentillav3n1.pdf. Acesso em: 10 ago. 2018.

MARTINS, Carmentilla das Chagas. Para além, através, da fronteira e do acordo: interações sociais no Oiapoque. 2014. 181 f. Tese (Doutorado em Ciências Sociais) - Instituto de Filosofia e Ciências Humanas, Programa de Pós-Graduação em Sociologia e Antropologia, Universidade Federal do Pará, Belém, PA, 2014.

MARTINS, José de Souza. Fronteira: a degradação do outro nos confins do humano. 2. ed. São Paulo: Contexto, 2009.

MUSOLINO, Álvaro Augusto Neves. Migração, identidade e cidadania Palikur na fronteira do Oiapoque e litoral Sudeste da Guiana Francesa. 2006. 187 f. Tese (Doutorado em Estudos Comparativos da América Latina e Caribe) - Ceppac, Universidade de Brasília, Brasília, DF, 2006.

NIMUENDAJU, Curt. Os índios Palikur e seus vizinhos. Manuscrito em fase de tradução por Thekla Hartmann. São Paulo: NHII/USP, [1926].

ODGERS, Olga; DELGADO, Amalia E. Campos."Ser móviles: la construcción de la identidad fronteriza a partir del acceso a la movilidad. In: BENLABBAH, Fatiha; MONTENEGRO, Silvia; AYAD, Nohma Bem (Coord.). Repensar las fronteras. Culturas: continuidades y diferencias. África - Europa - América Latina. Rosario: Instituto de Estudios Hispano-Lusos y la Universidad Nacional de Rosario, 2011. p. 133-44.

OLIVEIRA, Betiana de Souza. Dinâmicas sociais na fronteira entre o estado do Amapá e a Guiana Francesa: um estudo sobre Oiapoque, Vila Vitória do Oiapoque e Cayenne. 2011. 124f. Dissertação (Mestrado Integrado em Desenvolvimento Regional) - Universidade Federal do Amapá, Macapá, AP, 2011.

PINTO, Manoel de Jesus Souza. O fetiche do emprego: um estudo sobre as relações de trabalho de brasileiros na Guiana Francesa. 2008. 274p. Tese (Doutorado em Ciências: Desenvolvimento Socioambiental) - NAEA, Universidade Federal do Pará, Belém, PA, 2008.

SAHLINS, Marshal. O "pessimismo sentimental" e a experiência etnográfica: porque a cultura não é um "objeto" em via de extinção (parte II). Mana - Estudos de Antropologia Social do Museu Nacional, Rio de Janeiro, v. 3, n. 2, p. 103-50, out. 1997. 
SILVA, Gutemberg de Vilhena; RÜCKERT, Aldomar Arnaldo. A fronteira Brasil-França mudança de usos políticos-territoriais na fronteira entre Amapá (BR) e Guiana Francesa (FR). Confins, Paris, n. 7, p. 2-20, 2009. Disponível em: https://www.researchgate. net/publication/277151887_A_fronteira_Brasil-Franca_Mudanca_de_usos_politicoterritoriais_na_fronteira_entre_Amapa_BR_e_Guiana_Francesa_FR

VIDAL, Luz Boelitz. Mito, história e cosmologia: as diferentes versões da guerra dos Palikur contra os Galibi entre os povos indígenas da Bacia do Uaçá, Oiapoque, Amapá. Revista de Antropologia, São Paulo, v. 44, n. 1, p. 117-47, 2001.

\section{Sobre os autores:}

Venâncio Guedes Pereira - Mestrando do Programa de Pós-Graduação em Estudos de Fronteiras pela Universidade Federal do Amapá (PPGEF/UNIFAP). Especialista em Antropologia pela Universidade Cândido Mendes. Graduado em História pela UNIFAP. Dedica-se a pesquisas sobre fronteiras e comunidades indígenas em situações fronteiriças. E-mail: venanciogpereira@gmail.com

Carmentilla das Chagas Martins - Doutora em Ciências Sociais pela Universidade Federal do Pará (UFPA). Graduada em História pela Universidade Federal do Amapá (UNIFAP). Professora adjunta na Universidade Federal do Amapá, com atuação no curso de Licenciatura em História e no Mestrado Profissional em Estudos de Fronteiras (PPGEF/UNIFAP). Dedica-se a pesquisas sobre cidades, mobilidades e migração em território onde se localizam fronteiras internacionais na Amazônia. E-mail: carmentilla.c@gmail.com

Recebido em 15 de agosto de 2018 Aprovado para publicação em 22 de novembro de 2018 